\title{
Synthesis and Characterization of Ru(II) Tris(1,10-phenanthroline)-Electron
}

Acceptor Dyads Incorporating the 4-Benzoyl- $N$-methylpyridinium Cation or $N$ Benzyl- $N^{\prime}$-methylviologen. Improving the Dynamic Range, Sensitivity and Response Time of Sol-Gel Based Optical Oxygen Sensors.

Nicholas Leventis ${ }^{1, *}$, Abdel-Monem M. Rawashdeh ${ }^{2}$, Ian A. Elder ${ }^{2}$, Jinhua Yang ${ }^{2}$, Amala Dass $^{2}$ and Chariklia Sotiriou-Leventis ${ }^{2, *}$

1. NASA Glenn Research Center, Materials Division / Polymers Branch, 21000 Brookpark Road, M.S. 49-1, Cleveland, OH 44135; Tel.: (216) 433-3202; Email: Nicholas.Leventis@grc.nasa.gov

2. Department of Chemistry, University of Missouri-Rolla, Rolla, MO 65409; Tel.: (573) 341-4353; E-mail: cslevent@umr.edu

\section{Supporting Information}

Appendix S.1: $\quad$ Stern-Volmer Data from Bimolecular Quenching Studies

Appendix S.2: $\quad$ Proton assignment for NMR, ${ }^{1} \mathrm{H}$ NMRs and representative mass spectra

Appendix S.3: Synthesis of $N$-(4-ethynylbenzyl)-4,4'-bipyridinium tetrafluoroborate

Appendix S.4: Electronic absorption data in the MLCT region for all $\mathrm{Ru}(\mathrm{II})$ complexes

Appendix S.5: $\quad$ HOMO and LUMO of a Ru(II) complex analogous to 1-FB, 2-FB, 1 and 2.

Appendix S.6: Typical biexponential decay data, and data analysis

Appendix S.7: Comparison of the photoemission from 1-FB, 2-FB and 2 in frozen methanol matrix at $77 \mathrm{~K}$ and on Silica Aerogel at $77 \mathrm{~K}$ under Nitrogen

Appendix S.8: Room temperature emission of 2 from a poly(propylene sulfonate) film

Appendix S.9: Thermogravimetric Analysis (TGA) data of native silica aerogels

Appendix S.10: Comparative Photoemission of Silica Aerogels doped with 1-FB, and 2FB at $77 \mathrm{~K}$ under Oxygen and under Nitrogen 


\section{Appendix S.1 Stern-Volmer Data from Bimolecular Quenching Studies}

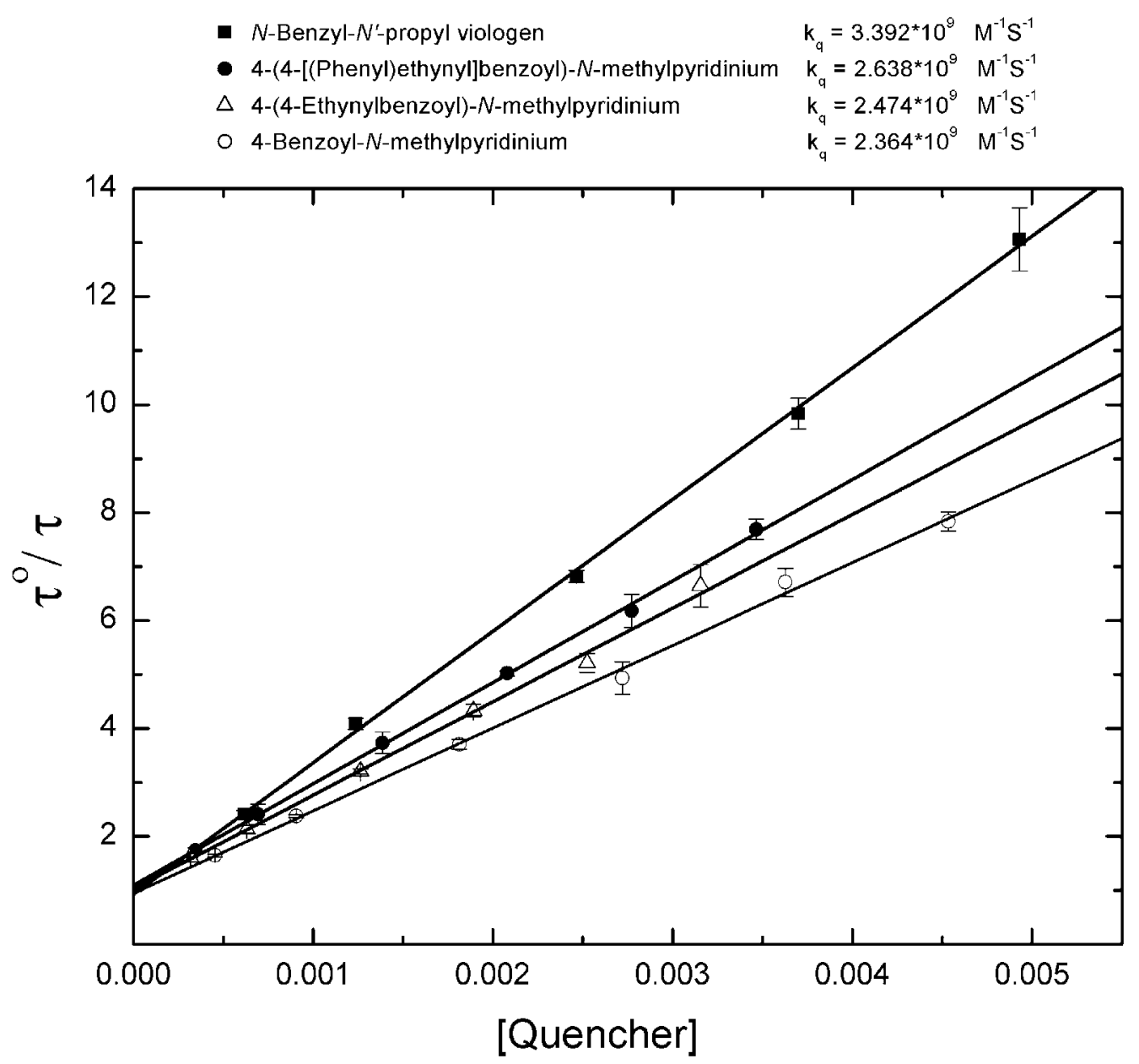

Figure S.1-1 Quenching of $\left[\mathrm{Ru}\left(2,2^{\prime} \text {-bipyridine }\right)_{2}(1,10-\text { phenanthroline })\right]^{2+}$ by selected quenchers in $\mathrm{CH}_{3} \mathrm{CN}$ containing $0.1 \mathrm{M}$ of $\mathrm{LiClO}_{4}$. Quenching rate constants (in $\mathrm{M}^{-1} \mathrm{~s}^{-1}$ ) are cited next to the corresponding quencher within the figure. (The native lifetime of the complex was $\tau^{0}=691 \pm 4 \mathrm{~ns}$, and was measured by time-resolved $\mathrm{N}_{2}$ laser flash spectroscopy, with the system described in the Experimental Section). 


\begin{tabular}{|c|c|c|c|}
\hline & {$\left[\mathrm{Ru}(\mathrm{phen})_{3}\right]^{2+}$} & Complex 1 & Complex 2 \\
\hline$f_{01}$ & 0.05 & 0.048 & 0.046 \\
\hline$k_{\mathrm{sv}-1}$ & 0.01631 & 0.0238 & 0.02605 \\
\hline$f_{02}$ & 0.95 & 0.952 & 0.954 \\
\hline$k_{\mathrm{sv}-2}$ & 2.50895 & 2.5948 & 1.2475 \\
\hline$R^{2}$ & 1 & 1 & 1 \\
\hline & & & \\
\hline
\end{tabular}

$$
\frac{I_{0}}{I}=\frac{1}{\frac{f_{01}}{1+k_{S V-1}\left[O_{2}\right]}+\frac{f_{02}}{1+k_{S V-2}\left[O_{2}\right]}}
$$

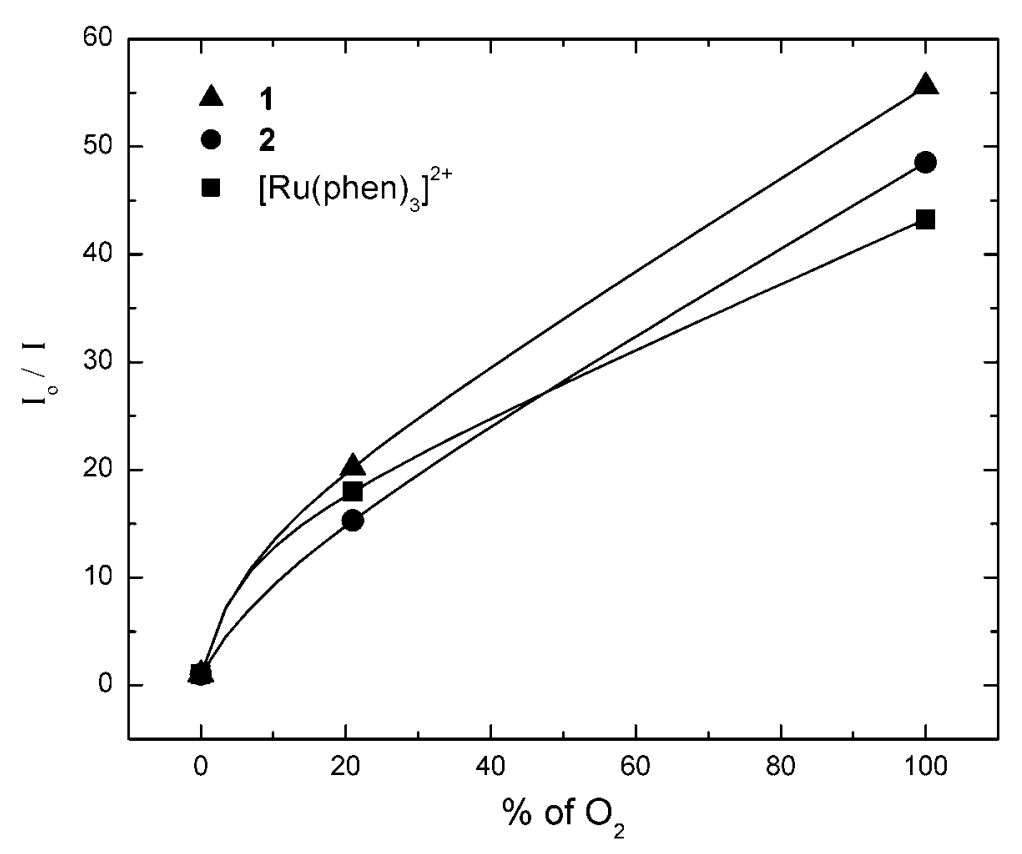

Figure S.1-2 Room temperature quenching of the photoemission of aerogels doped with complexes 1, 2, and $\left[\operatorname{Ru}(1,10 \text {-phenanthroline })_{3}\right]^{2+}$ by oxygen. The three points correspond to $0 \%$ oxygen (aerogels under $\mathrm{N}_{2}$ ), $21 \%$ oxygen (aerogels in air) and $100 \%$ oxygen (aerogels under pure oxygen). 
Appendix S.2 Spectral Identification Data for Selected Compounds

S.2.1

${ }^{1} \mathrm{H}$ NMR Analysis of $\left[\mathrm{Ru}(\text { phen })_{3}\right]^{2+}$,

$[\mathrm{Ru} \text { (phen })_{2}$ (2,8-dibromo-1,10-phenanthroline) $]^{2+}$, 1-FB, 1, 2-FB and 2.

Structure for proton assignment $(-\mathrm{X} \neq-\mathrm{H})$

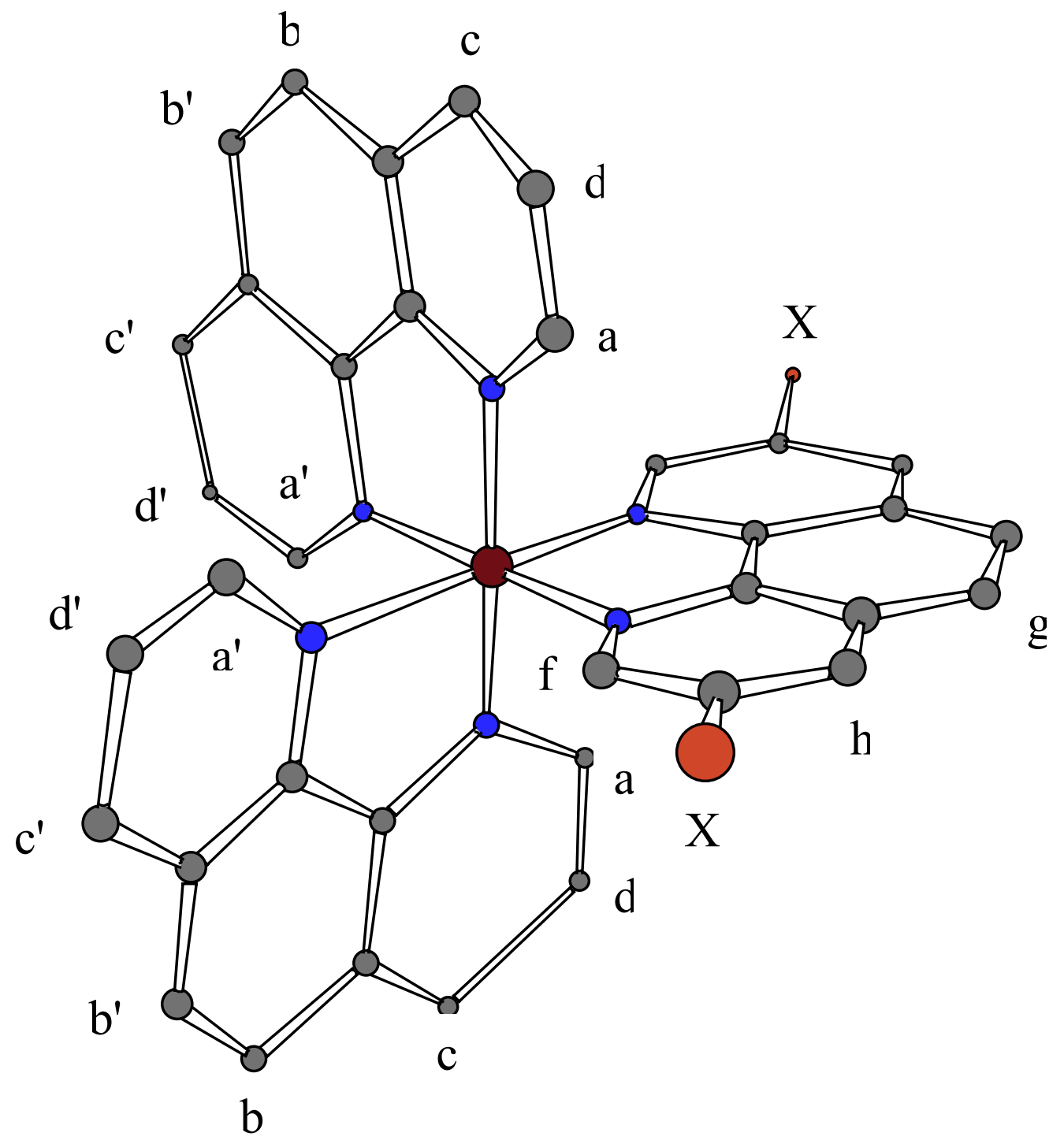


Structures for proton assignment $(-\mathrm{X} \neq-\mathrm{H})$ (continued)

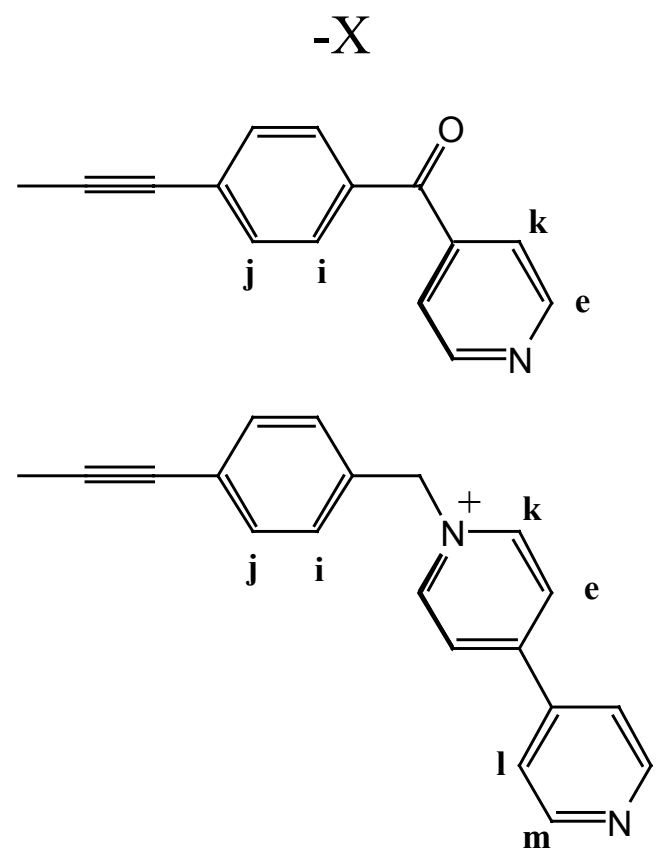

: for complexes 1-FB and $\mathbf{1}$

: for complexes $\mathbf{2}-\mathbf{F B}$ and $\mathbf{2}$ 

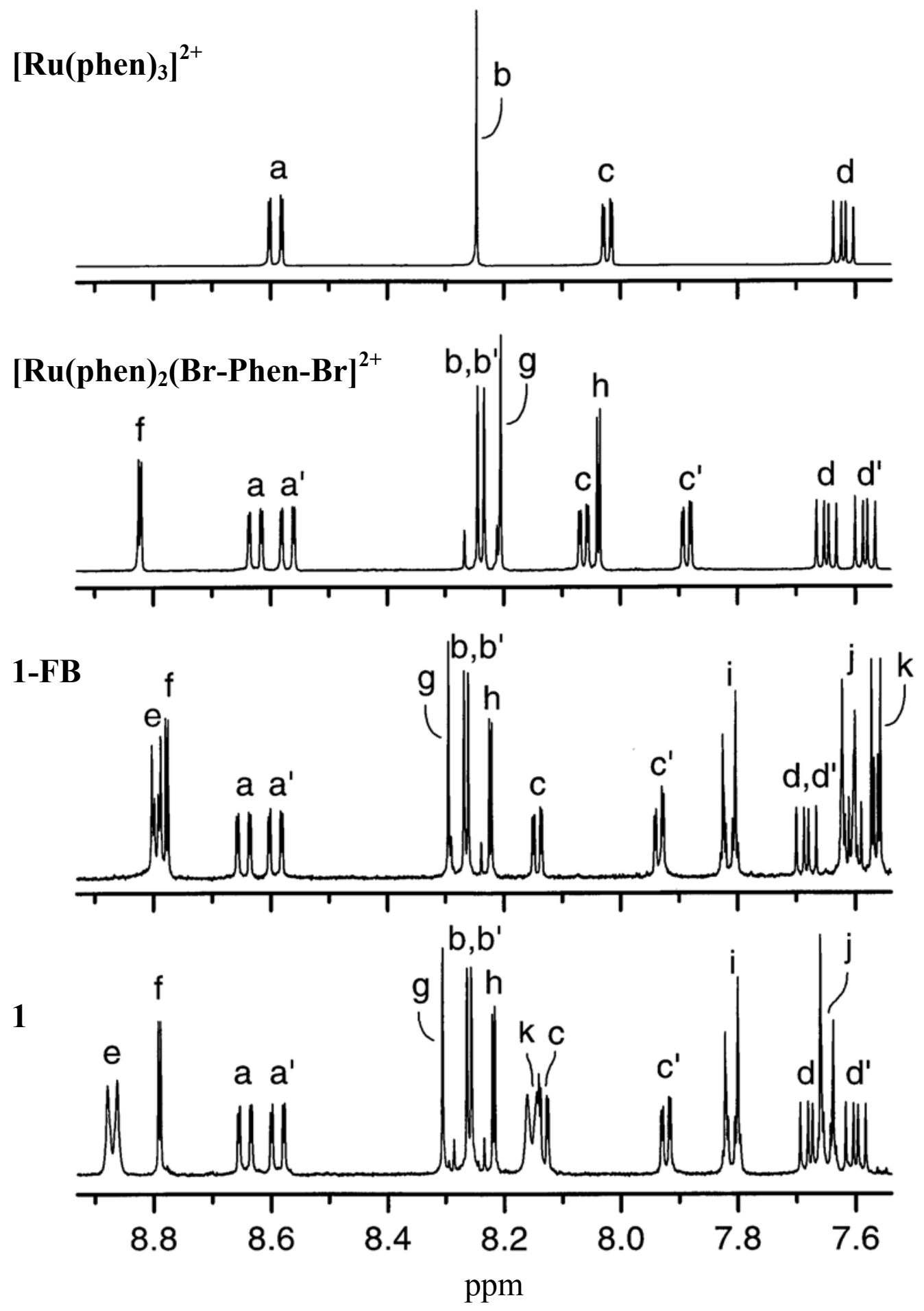

Figure S.2-1 $400 \mathrm{MHz}{ }^{1} \mathrm{H}-\mathrm{NMR}$ spectra (aromatic region) in $\mathrm{CD}_{3} \mathrm{CN}$ 


\section{2-FB}

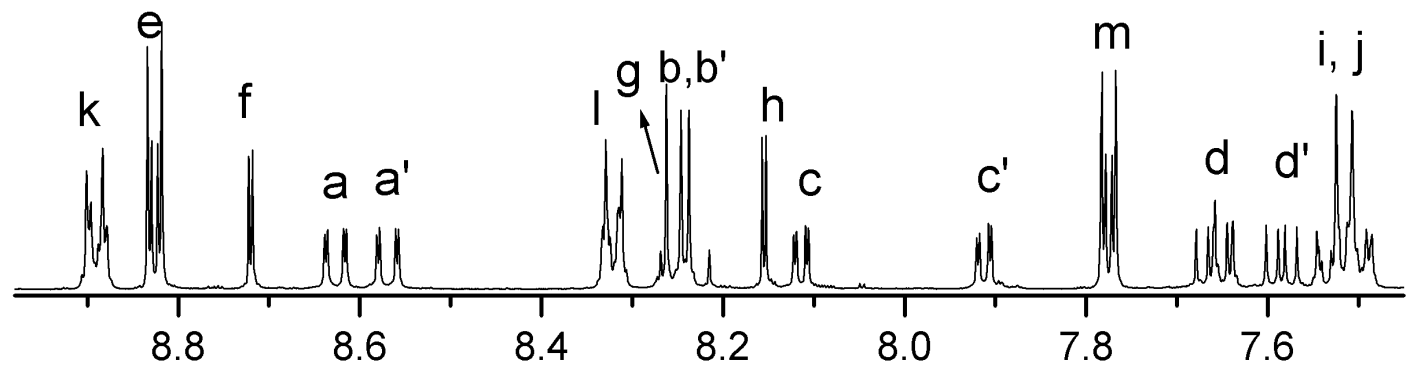

2

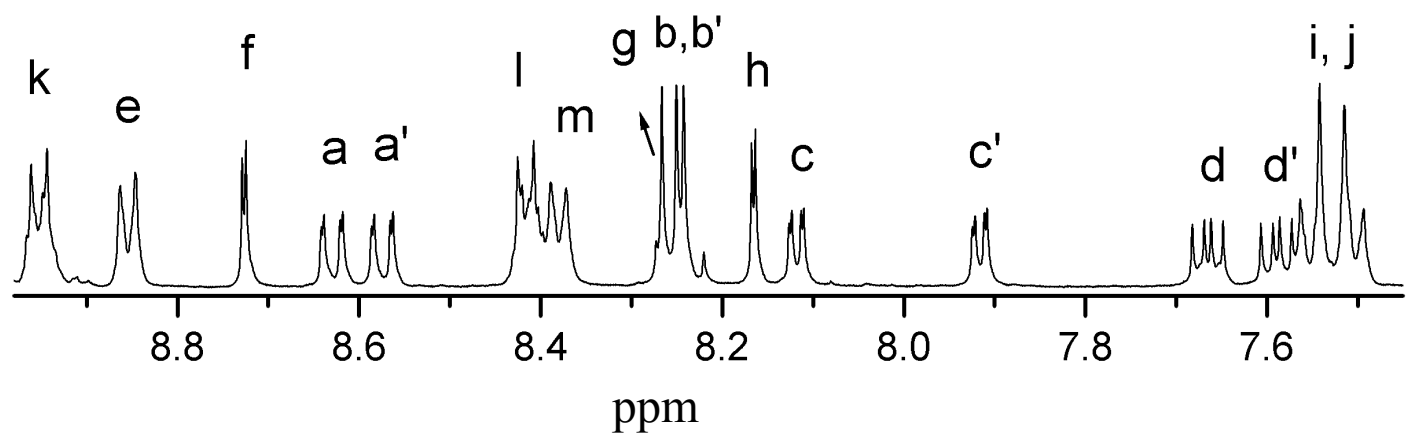

Figure S.2-1 (continued) 


\section{S.2.2 Examples of Time-of-Flight Nanospray Mass Spectrometric Analysis of Selected Ruthenium Complexes.}
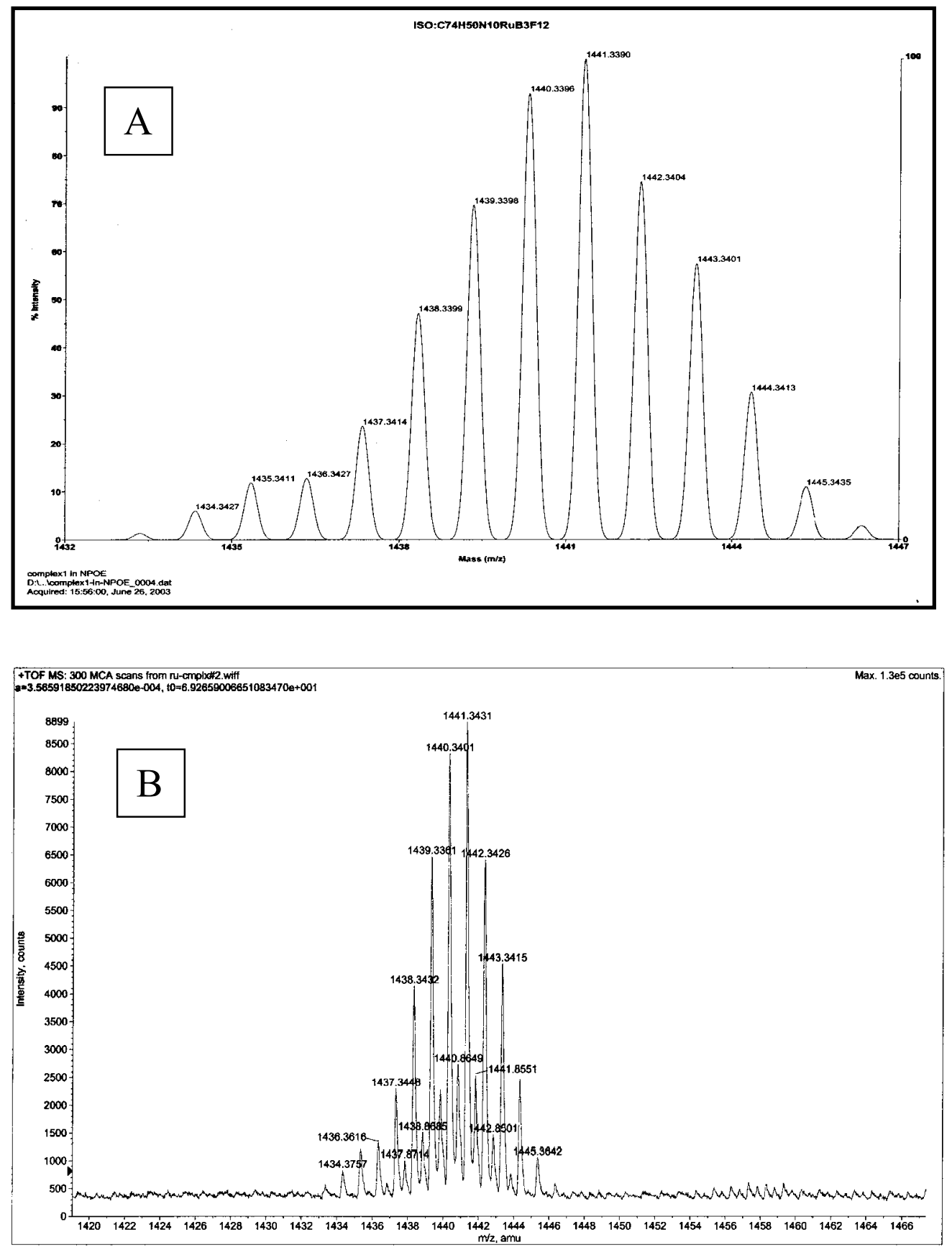

Figure S.2-2 Analysis of Complex 2-FB $\left(\mathrm{C}_{74} \mathrm{H}_{50} \mathrm{~N}_{10} \mathrm{RuB}_{3} \mathrm{~F}_{12}\right)^{1+}$. A. Theoretical spectrum (theoretical mass: 1441.3390). B: Experimental spectrum (mass: 1441.3431). 

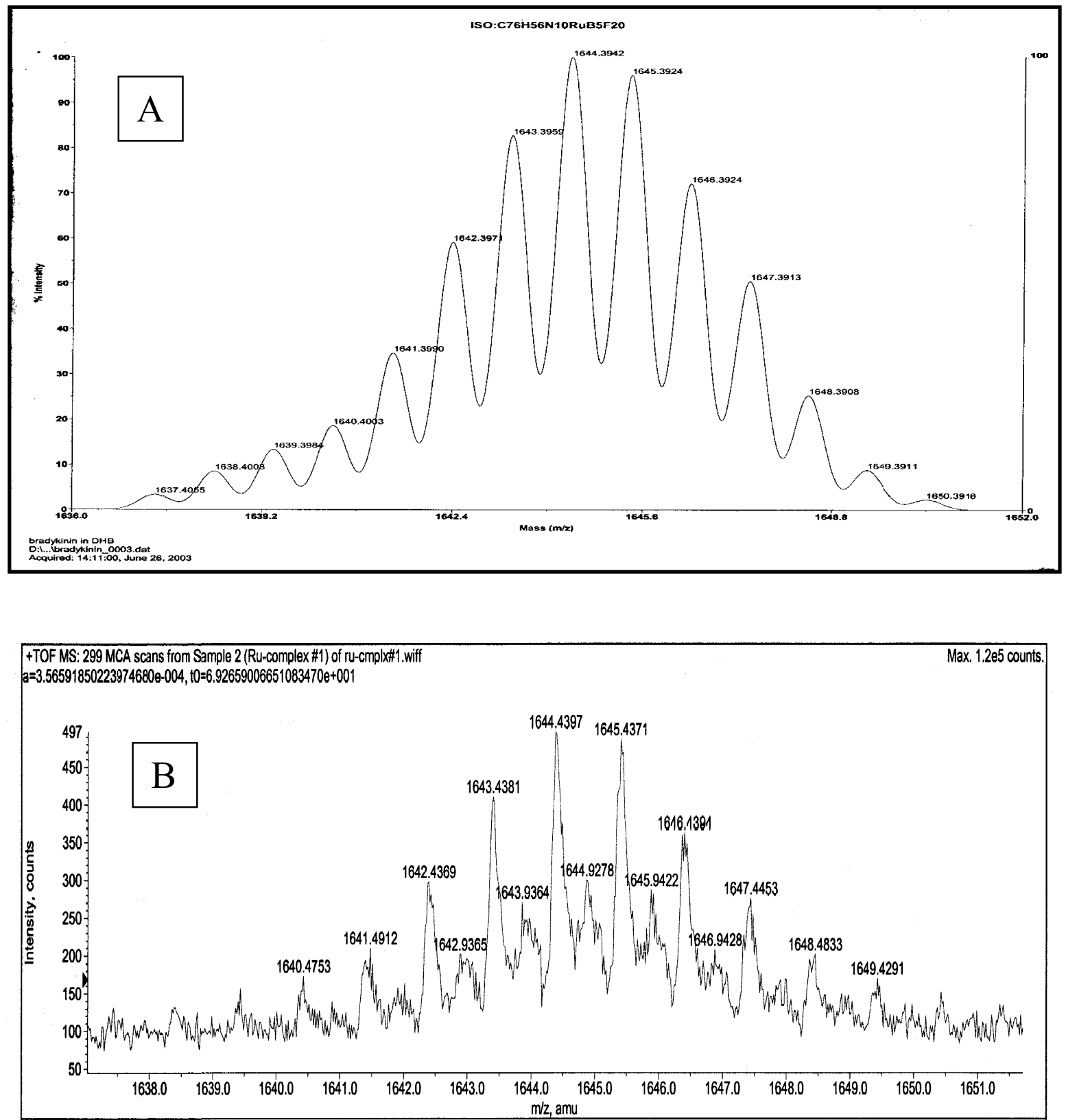

Figure S.2-3 Analysis of Complex $2\left(\mathrm{C}_{76} \mathrm{H}_{56} \mathrm{~N}_{10} \mathrm{RuB}_{5} \mathrm{~F}_{20}\right)^{1+}$. A. Theoretical spectrum (theoretical mass: 1645.3924). B: Experimental spectrum (mass: 1645.4371). 


\section{Appendix S.3 Synthesis of N-(4-ethynylbenzyl)-4,4'- bipyridinium tetrafluoroborate}
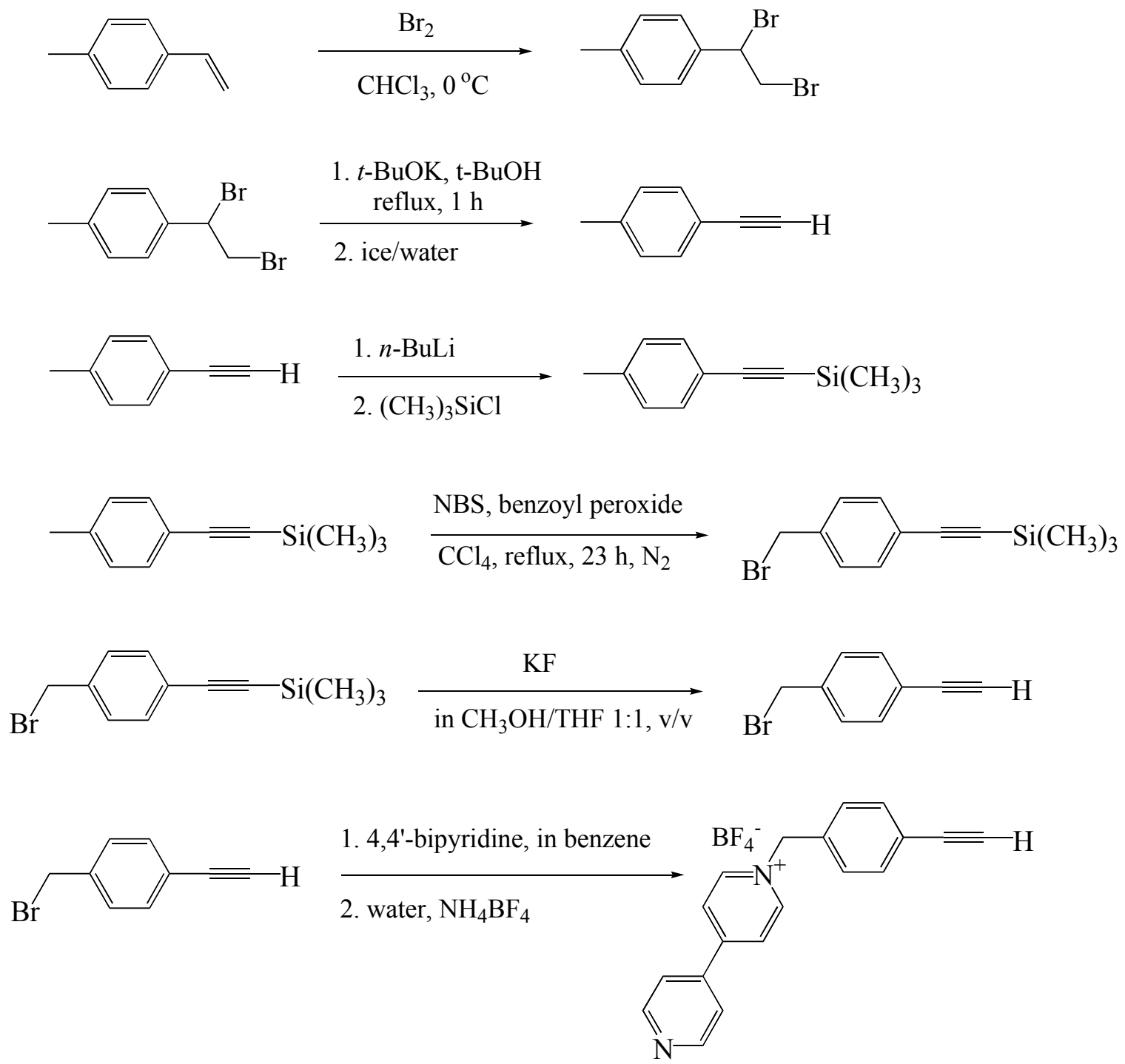
Appendix S.4 Comparative Absorption Spectroscopy in the MLCT Region for 1-FB, 1, 2-FB, 2 and $\left[\mathrm{Ru}(\text { phen })_{3}\right]^{2+}$ in $\mathrm{CH}_{3} \mathrm{CN}$ and $\mathrm{CH}_{3} \mathrm{OH}$

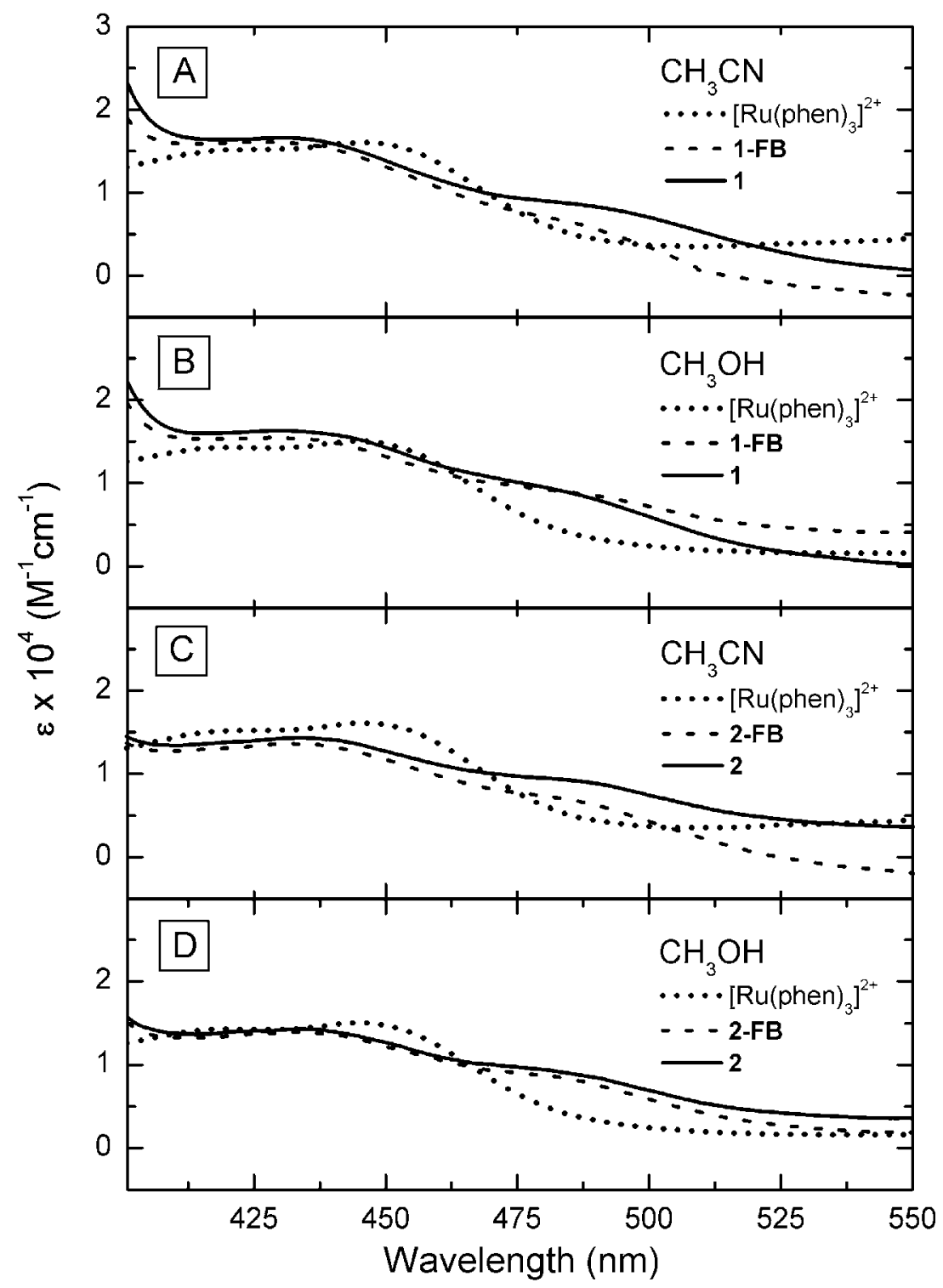

Figure S.4-1 MLCT region absorption spectra of $\mathrm{Ru}(\mathrm{II})$ complexes in solution at room temperature. A: $[\mathbf{1}]=9.95 \times 10^{-6} \mathrm{M} ;[\mathbf{1 - F B}]=9.65 \times 10^{-6} \mathrm{M} ;\left[\left[\mathrm{Ru}(\mathrm{phen})_{3}\right]^{2+}\right]=$ $1.20 \times 10^{-5}$ M. B: $[\mathbf{1}]=1.66 \times 10^{-5} \mathrm{M} ;[\mathbf{1 - F B}]=1.45 \times 10^{-5} \mathrm{M} ;\left[\left[\mathrm{Ru}(\mathrm{phen})_{3}\right]^{2+}\right]=$ $2.40 \times 10^{-5}$ M. C: $[2-F B]=1.16 \times 10^{-5}$ M; [2] $=1.39 \times 10^{-5}$ M. D: $[\mathbf{2}-\mathbf{F B}]=1.15 \times$ $10^{-5} \mathrm{M} ;[2]=1.16 \times 10^{-5} \mathrm{M}$. 


\section{Appendix S.5 HOMO and LUMO of a Ru(II) complex analogous to 1-FB, 2-FB, 1 and 2.}
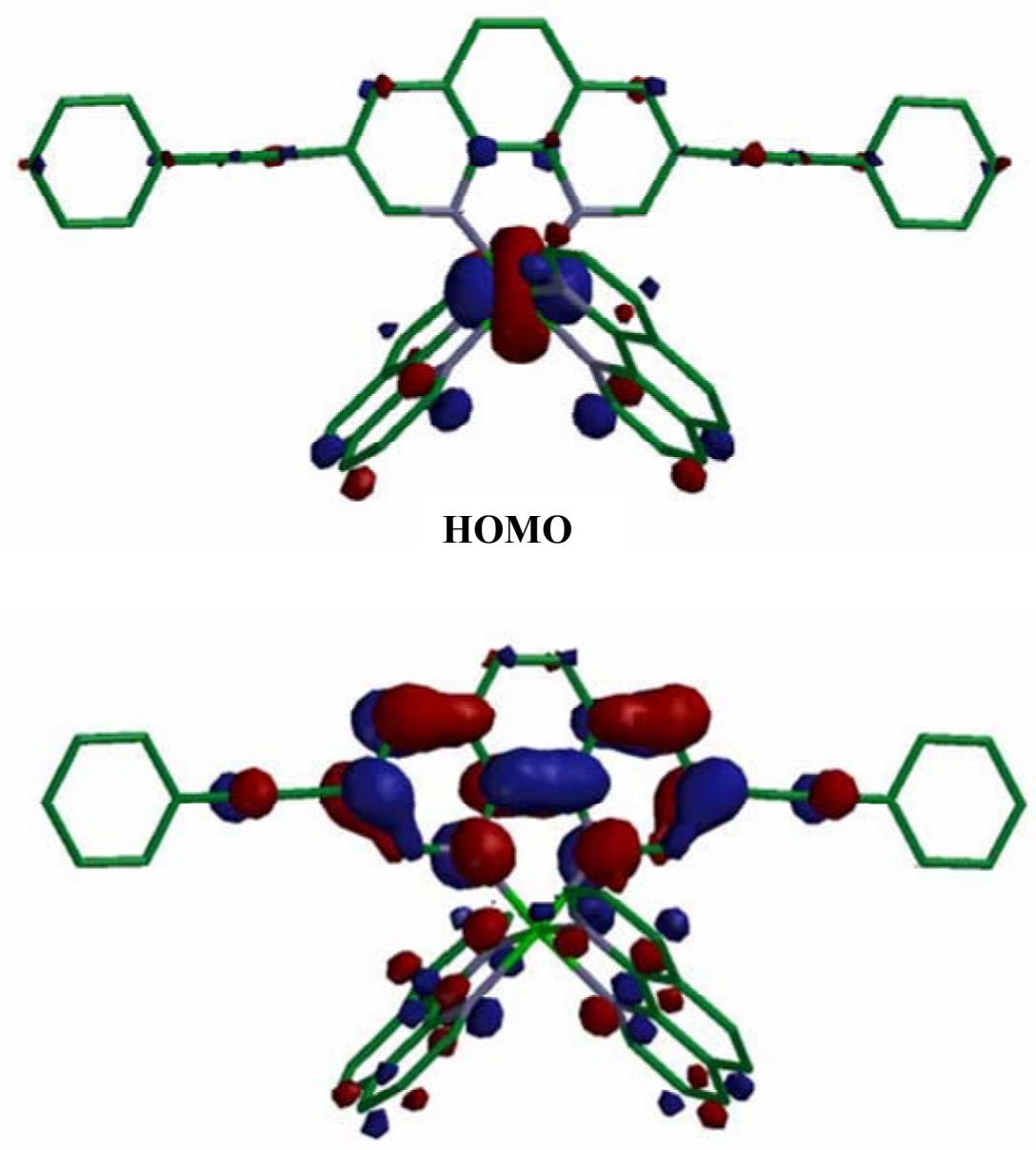

LUMO

Figure S.5-1 3D visualization of the HOMO and the LUMO of bis(1,10phenanthroline)mono(3,8-bis(4-ethynylphenyl)-1,10-phenanthroline) ruthenium(II). The geometry was optimized first using semi-empirical (PM3) calculations, and then the HOMO and the LUMO were calculated using HF ab initio calculations with the $3-21 \mathrm{G}^{*}$ basis set. Clearly, the HOMO is metal-centered, while the LUMO is localized over the 3,8-disubstituted 1,10-phenanthroline. It is noted further that delocalization does not extend beyond the triple bond, even though the phenyl group is at the same plane with the $\pi$ system of 1,10 -phenanthroline. 


\section{Appendix S.6 Typical biexponential decay data, and data}
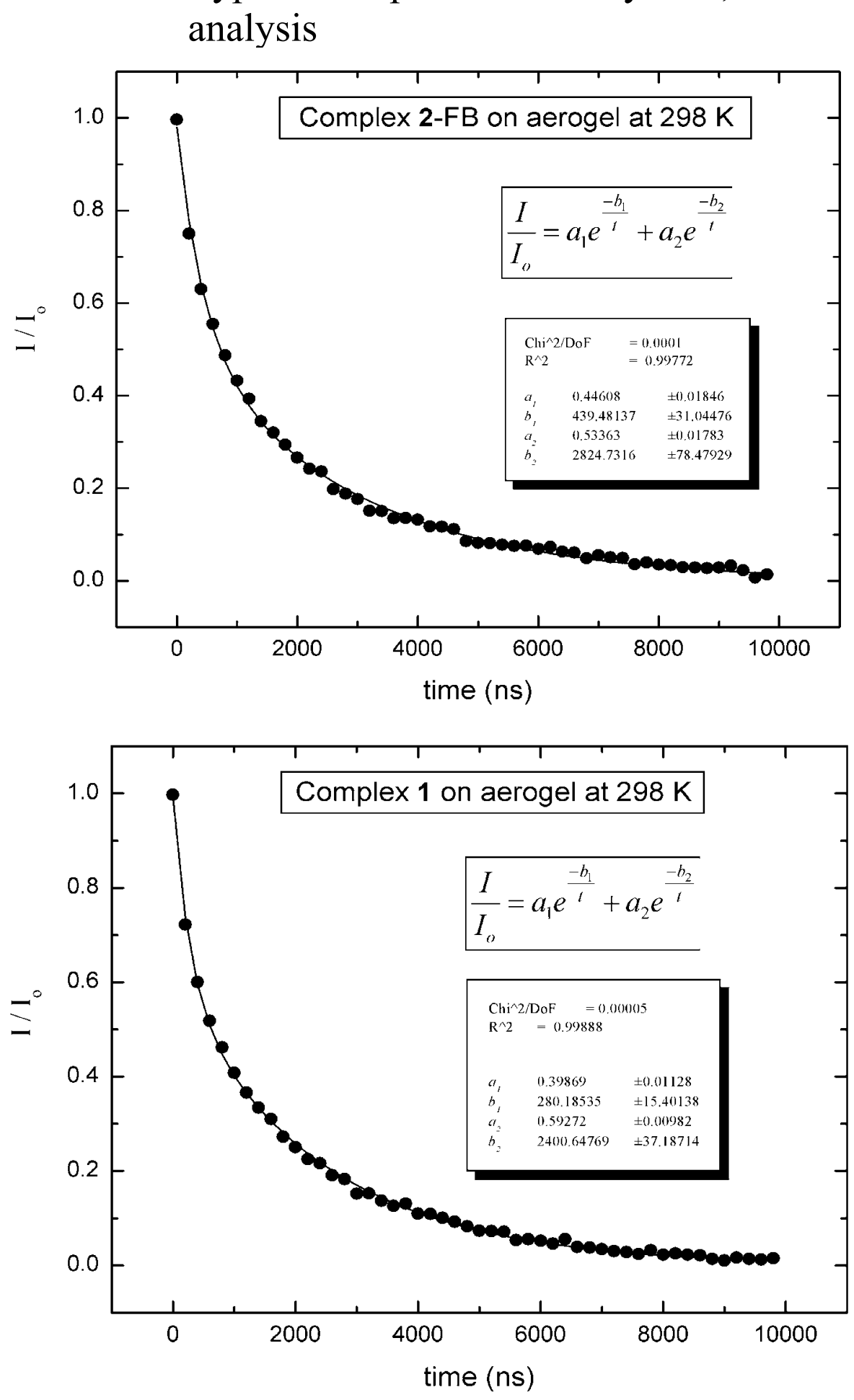

Figure S.6-1 Room temperature emission decay data from two aerogels doped with 1FB and 2, respectively. $\left(\lambda_{\mathrm{ex}}=425 \mathrm{~nm}\right.$.) 
Appendix S.7 Comparison of the photoemission from 1-FB, 2FB and $\mathbf{2}$ in frozen methanol matrix at $77 \mathrm{~K}$ and on Silica Aerogel at $77 \mathrm{~K}$ under Nitrogen

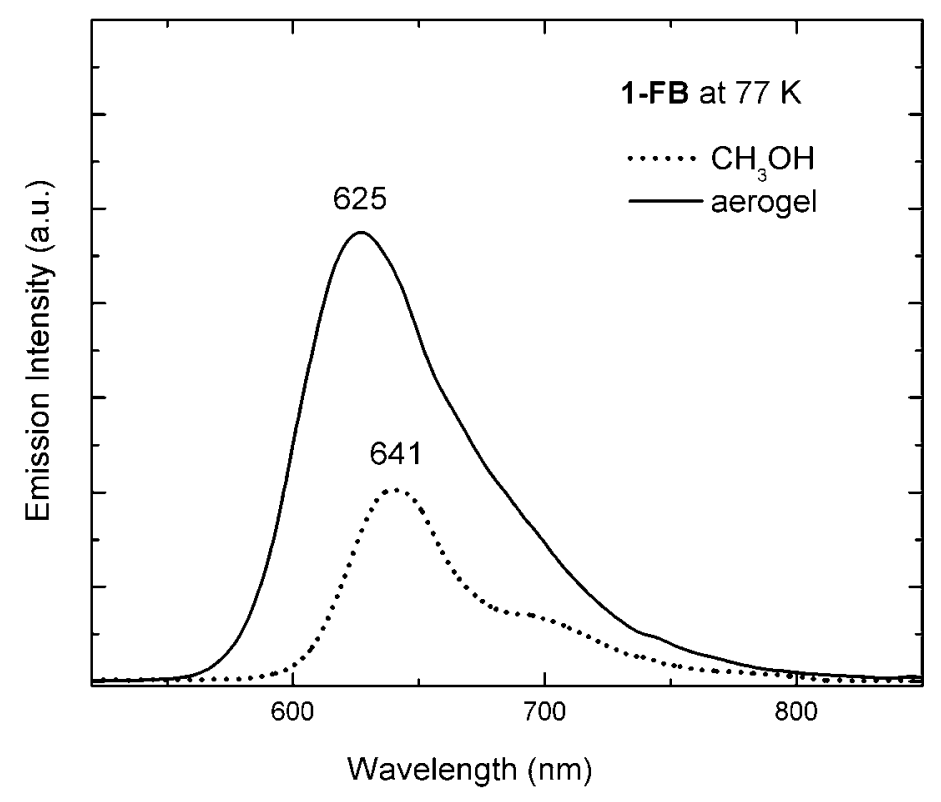

Figure S.7-1 Emission data for 1-FB. Spectra have been scaled for clarity; relative intensities are arbitrary.

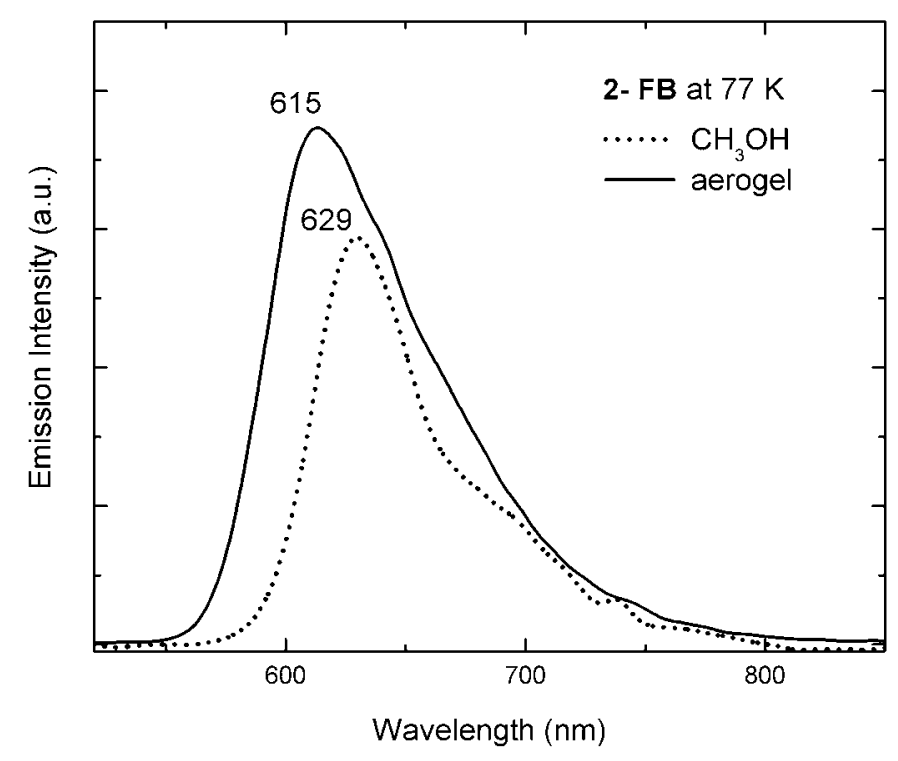

Figure S.7-2 Emission data for 2-FB. Spectra have been scaled for clarity; relative intensities are arbitrary. 


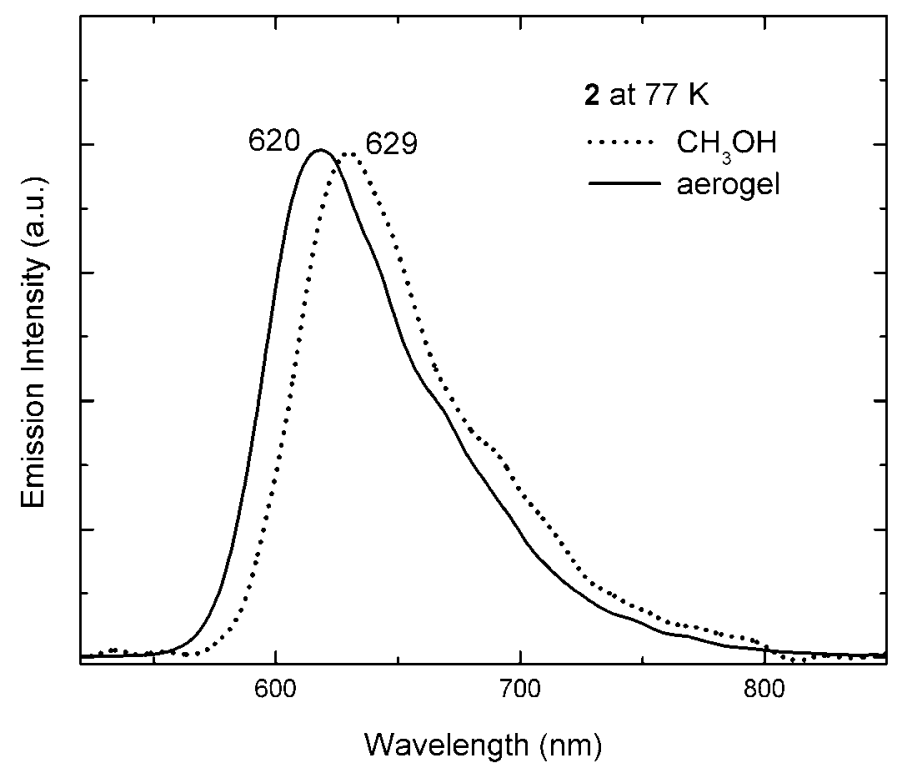

Figure S.7-3 Emission data for 2. Spectra have been scaled for clarity; relative intensities are arbitrary. 


\section{Appendix S.8 Room temperature emission of 2 from a poly(propylene sulfonate) film}

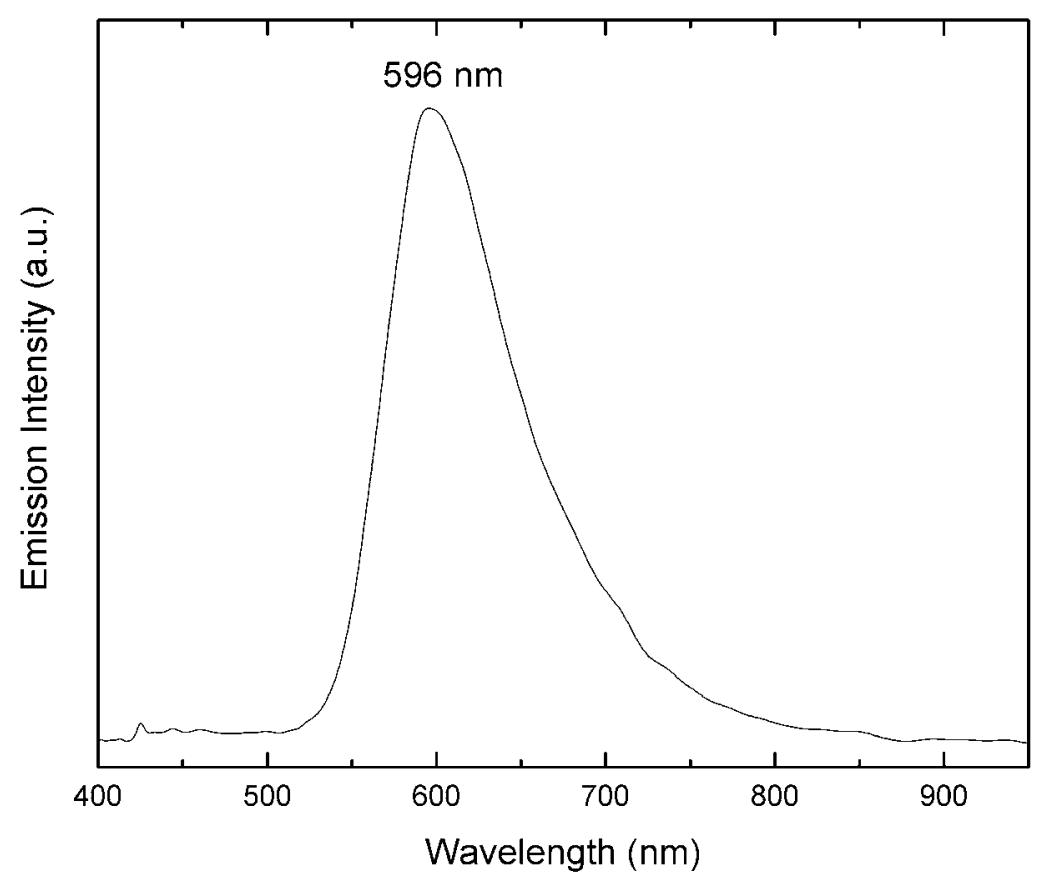

Figure S.8-1 Room temperature emission from a film made by mixing an aqueous solution of $2\left(\sim 10^{-5} \mathrm{M}\right)$ and an aqueous solution of poly(propylene sulfonate) (PPS), then casting the solution on a glass slide, and lifting the film after it was dried at $40{ }^{\circ} \mathrm{C}$ for 24 h. 


\section{Appendix S.9 Thermogravimetric Analysis (TGA) data of native silica aerogels}

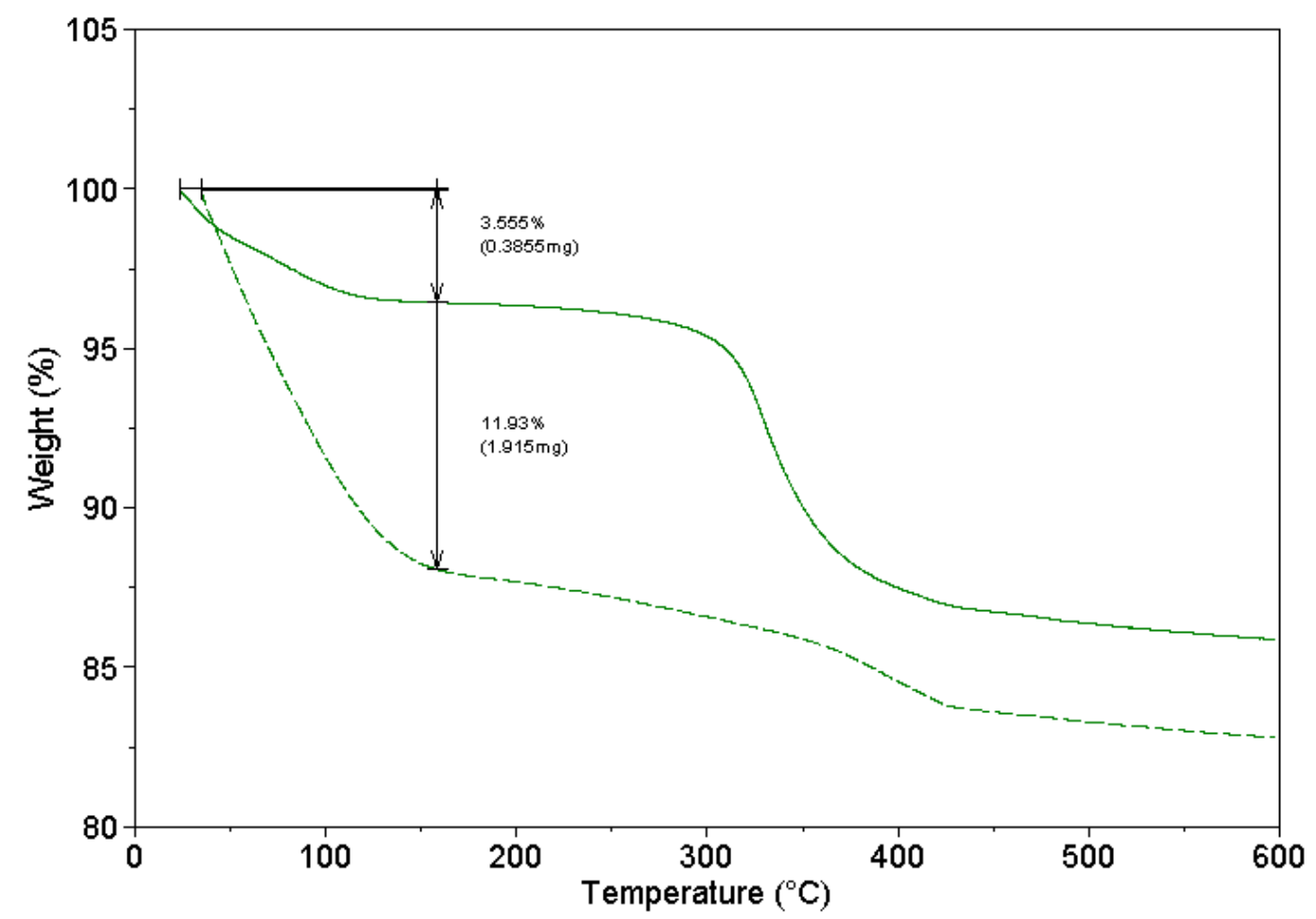

Figure S.9-1 TGA data for two native aerogel samples: : no additional hydrogel washings with water; - - - - : hydrogels washed with water as described in the Experimental Section. Instrumentation: TA Instruments. TGA 2950 . Heating rate: $10{ }^{\circ} \mathrm{C}$ per minute; Range: $24{ }^{\circ} \mathrm{C}$ to $600{ }^{\circ} \mathrm{C}$. Weight loss calculated at $150{ }^{\circ} \mathrm{C}$. 


\section{Appendix S.10 Comparative Photoemission of Silica Aerogels doped with 1-FB, and 2-FB at $77 \mathrm{~K}$ under Oxygen and under Nitrogen}

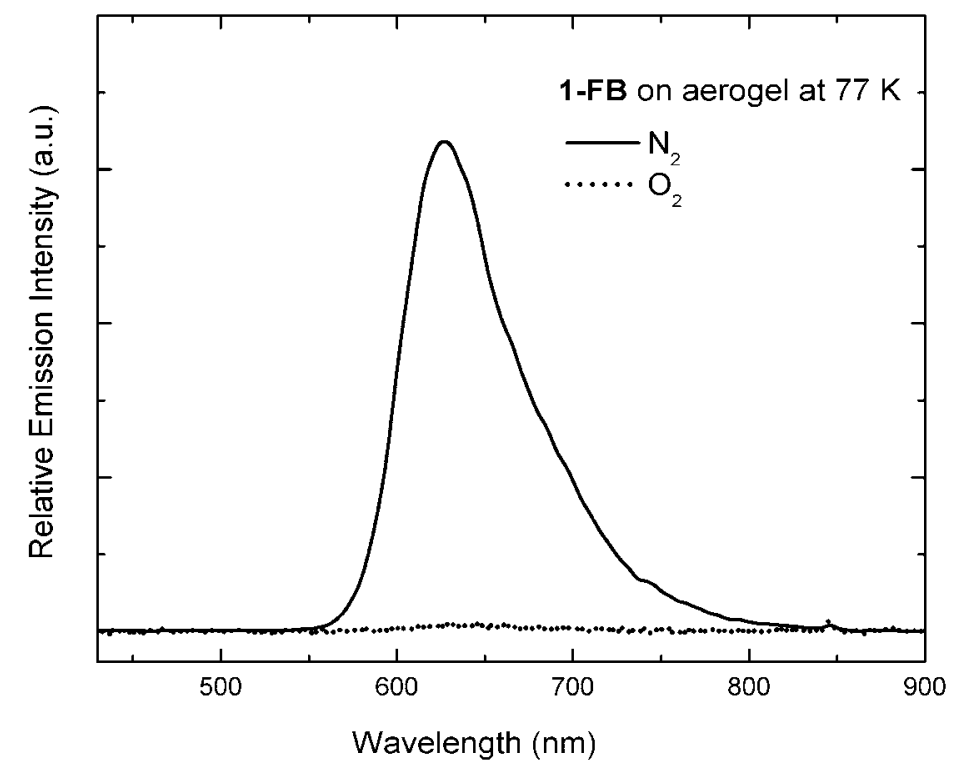

Figure S.10-1 Emission data at $77 \mathrm{~K}$ of a silica aerogel doped with 1-FB.

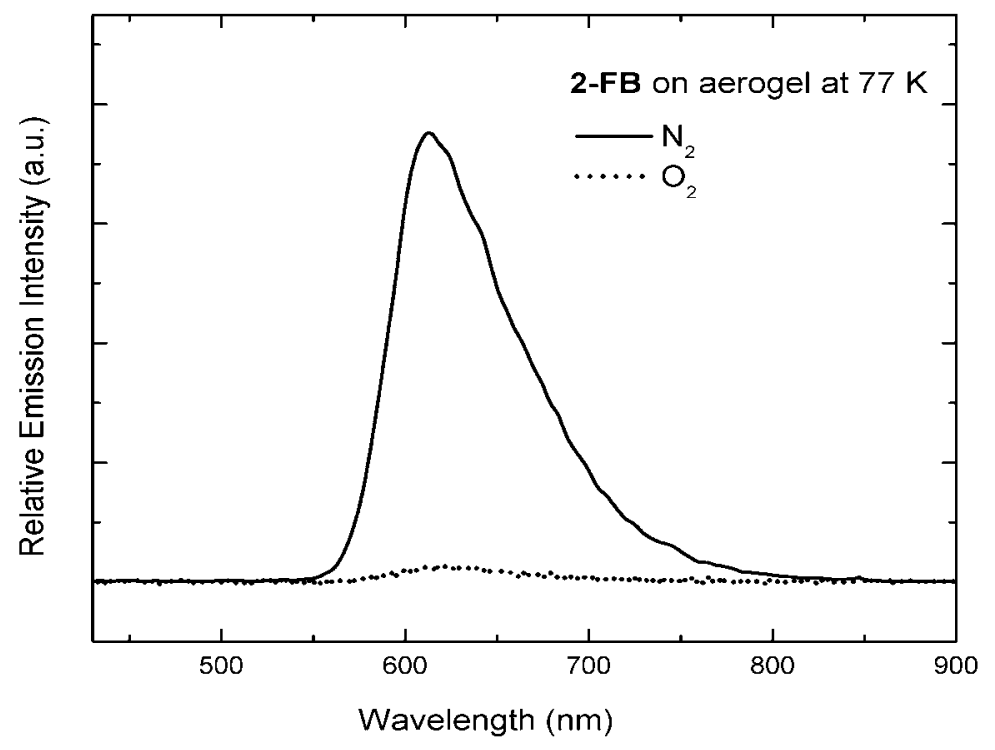

Figure S.10-2 Emission data at $77 \mathrm{~K}$ of a silica aerogel doped with 2-FB. 